\title{
MEASURING CONVERSION OF INDUSTRIAL LAND AFTER SALE
}

\section{PETER ROSSINI, PAUL KERSHAW and VALERIE KUPKE University of South Australia}

\begin{abstract}
This paper quantifies the take up of vacant industrial land, in terms of its conversion from vacant to improved land, for the metropolitan area of Adelaide. It involves the comparison of sales for a five year period between 1991 and 1995 with the SA Valuer General's Valuation List for 1996. The analysis reveals the generally low level of take up in terms of conversion of land, sold as vacant industrial land, to land which is improved. The paper begins by briefly discussing alternative methodologies for estimating demand, in terms of take up rates, and ends by summarising the implications of the study for demand forecasting in general.
\end{abstract}

Keywords: Industrial land, take-up rates, sales volume, spatial analysis.

\section{INTRODUCTION}

Throughout Australia, patterns of demand for urban land have changed substantially in the last decade. This also applies to demand for industrial land. The term 'industrial' has become ambiguous as distinctions between commercial, industrial and retail land use practices become less clear and increased flexibility in planning controls is sought in order to generate economic and administrative advantages (Blair \& Yardley, 1994). Such change also reflects the developing and increasingly competitive nature of the industrial sector. For states such as South Australia (SA), which has a substantial reliance on manufacturing as a base for job growth, industrial land management practices which adequately provide for such change are critical (Australian Bureau of Statistics, 2003; 2004; Stimson, O'Connor \& Taylor, 1997; Stimson, 2001). Writers such as Gibb (2004) and Tsolacos (1997) have emphasised the need for a considered and informed approach to the assessment of derelict and vacant land in order to establish appropriate policy priorities in terms of industrial land development. Other writers have identified the importance of land owner behaviour in terms of passive or active attitudes towards land development (Adams, Russell, Russell -Taylor, 1995; Adams, Disberry, Hutchinson \& Munjoma, 2001). During the 1990s, there were perceived constraints in SA's land management which, it was thought, could adversely affect the state's long term economic future; namely the long term supply of adequate and appropriate vacant land suitable for future industrial use. This 
established a need for information, not just in terms of volumes of land transacted, but also in actual take up or conversion rates of industrial land.

As such, this paper reports on a pragmatic approach to determining the take up of vacant industrial land which reflects the level of data available at the time of the study. It is based only on the take up of vacant industrial land which sold within a five year period and, as such, is using sales evidence to quantify the change industrial land use. It estimates the conversion of vacant industrial land to an improved state by considering what happened to vacant industrial land properties after sale within the Adelaide Statistical Division (ASD) between the years 1991 and 1995. Properties which had changed from the vacant land use code which existed at the point of sale, to a different land use code thereafter, are considered to be 'taken-up'. The paper begins by briefly discussing alternate methods of establishing industrial take-up. It then proposes a methodology using demand analysis based on sales volume supported by analysis of physical improvements to the land. Vacant land is defined as vacant blocks of industrially zoned land which have not had any development consents consigned to them (Blair \& Yardley, 1991). Finally, the paper describes the spatial distribution of the take-up within the ASD.

\section{ESTABLISHING INDUSTRIAL TAKE-UP RATES}

The estimation of the demand for vacant industrial land requires analysis of take-up rates over a time period. The first practical difficulty in this is to define and measure take-up. This is a particular problem faced whenever property resources are analysed. Put simply, land is not consumed in the same way as other goods. Arguably, once land is made available for industrial use, it remains available. While it may be built upon and used, these improvements can always be removed making the site equally as useful at a later stage. This ability to keep re-using the asset makes estimates of supply and demand somewhat difficult, unless a complex inventory model is used.

It may be that the only effective way to estimate the supply and demand for industrial land is to develop a long term inventory model to enable accurate estimates of demand, based on changes in inventory and estimates of supply based on the current inventory. Even this will present some difficulties due to the opportunity to substitute between vacant and improved industrial stocks.

In the absence of such an inventory model, it is necessary to make estimates of take-up based on other systems. These may be broadly categorised as:

1. Quasi inventory models

2. Models based on physical take-up or construction

3. Models based on the sale of vacant land stocks. 


\section{Quasi inventory models}

The available literature suggests a wide range of quasi-inventory models which can be used to estimate industrial supply and take-up. Jortberg (1996) and Wincott and Mueller (1995) suggest models based on readily available statistics, adjusted by use ratios. Typically these involve population or employment rates adjusted by floor-space ratios. A similar method is suggested by Blair Yardley (1991) to estimate the demand for vacant industrial land in Sydney. They suggest that they:

'used the most recent (July 1989) five year forecasts of industrial output and employment available from NIEIR (National Institute of Economic and Industry Research). These were translated into land requirements via employment densities.'

This was a secondary method employed by Blair \& Yardley after using an actual inventory of industrial land based on local council records.

Wheaton and Torto (1990) used a survey of industrial buildings in 52 major metropolitan areas in the United States to develop an investment model for industrial real estate while Ball (1989) used a survey to examine issues in vacant industrial premises in Stoke-onTrent. While neither paper suggests that these are complete inventories, a sample methodology may be an appropriate quasi-inventory methodology.

In theory, the quasi inventory method could be employed in SA, based on the use of the Valuation List produced by the Valuer General. The list classifies parcels of land in SA by use and development control zone. An annual inventory of vacant industrial land could be produced using each Valuation List. This would provide an extremely accurate estimate of the current supply of vacant industrial land, as changes to the list could be used to establish take-up and creation rates. Unfortunately, at the time of this study, the Valuation List was not available in a format which would allow for this type of analysis.

\section{Take-up estimates based on building approvals or evidence of building}

Take-up rates based on building approval data should provide highly accurate take-up rates. In their study of Sydney's vacant industrial land situation, Blair and Yardley (1991) used development consents to establish that a vacant site had been developed. Blair and Yardley only referred to Local Government Areas (LGA) where more than 10 per cent of land stocks were vacant. Within these LGAs, data was collected from council consent registers. While consent does not necessarily lead to development, this method seems to have been adopted because 'consents were easier to obtain than building commencements' (Blair \& Yardley, 1991). Two alternative methods used by Blair and Yardley (1991) involved using Landsat imagery, charting physical changes and the use of Australian Bureau of Statistics commencement data. The commencement statistics recorded the value (in dollars) of new building activity. These were then converted to building commencements by adjusting for inflation and dividing by appropriate floor space ratios. However in SA, no accurate statistics of the volumes of vacant industrial land have been developed. Building commencement figures are too general to be of use. As such, accurate figures would require detailed analysis of commencement records from each local council, which again was considered beyond the scope of this study. 
Take-up estimates based on sales of vacant industrial land

The use of transaction data to analyse trends in property markets is wide spread. Major property firms produce reports on various market segments including industrial land. Sales analysis is also the focus of many government reports used to assist in planning policy. Transaction data is readily available. It is generally accurate and provides a realistic picture of real estate markets. Most sales reflect market transactions; a change in ownership as a result of market exposure. The major problem with sales analysis is that the sale of land may not result in any physical take-up. Some purchasers are speculators. Some purchase for very long term plans, which in the end may not be required. Still other purchasers find other opportunities or changed circumstances. Such owners are collectively described as 'passive' land owners (Adams et al, 1995; Adams et al, 2001). Put simply, the sale of the land may not imply take-up. If sales volumes are high, but physical take-up is low, then estimates using sales volumes will suggest that land stocks will be reducing at a significantly greater rate than is physically happening. A secondary problem with sales analysis is that land may be re-zoned or taken-up using non industrial land uses. While this is still significant from an inventory point of view, such situations are likely to overestimate demand for industrial purposes, as some of the land is actually demanded for a different purpose.

Therefore, it is suggested that due to these problems, demand analysis based on sales volume should be supported by further analysis to establish the physical take-up of sales. This analysis does not capture land taken-up from long term land holders (as an inventory or physical take-up estimate does), but should still provide a more realistic estimate than sales analysis alone.

\section{SALES VOLUME AND TAKE-UP RATES IN THE ASD}

A procedure was adopted which involved comparing details of the property at the point of sale with the details listed on the Valuation List. The 1996 Valuation List (produced at the end of the 1996 financial year) was the most recent available. All properties which were listed as vacant industrial sales for the years 1991 to 1995 were used. Sales after 1995 were not used, as it was considered that the time between the sale and the Valuation List would be insufficient to indicate a take-up. In each case, the Land Use Code, Improvements Code and Zoning Code were compared between the sale details and the 1996 Valuation List. Properties which had changed from a vacant land use code to a different code were considered to be taken-up. It is important to note that some properties had a change of code but remain unimproved. Change of use does not imply development. It was expected that properties selling in 1991 would have the highest take-up rates and that the rate would reduce as the time between the date of sale and the date of the Valuation List decreased. 


\section{GENERAL TAKE-UP RATES}

The results from the analysis of sales take-up are summarised in Table 1 and Table 2.

Table 1: Volume of land taken up (hectares): 1991-1995

\begin{tabular}{||l|l|l|l|l|l|l||}
\hline \hline LAND TAKEN-UP & $\mathbf{1 9 9 1}$ & $\mathbf{1 9 9 2}$ & $\mathbf{1 9 9 3}$ & $\mathbf{1 9 9 4}$ & $\mathbf{1 9 9 5}$ & TOTAL \\
\hline NO & 63.91 & 50.01 & 23.41 & 46.41 & 47.07 & 230.82 \\
\hline YES & 35.23 & 14.46 & 10.87 & 55.62 & 26.94 & 143.11 \\
\hline Unknown & 2.00 & 3.64 & 17.94 & 2.71 & 7.00 & 33.29 \\
\hline TOTAL & 101.15 & 68.11 & 52.21 & 104.74 & 81.01 & 407.22 \\
\hline \hline
\end{tabular}

It is evident that a significant volume of the land which had been sold had not changed use, in that it had remained vacant. Of the 407 hectares sold between 1991 and 1995, some 230 hectares were confirmed as remaining vacant in 1996, while only 143 hectares had changed use and been taken-up (the use of 33 hectares is unknown).

These results have been converted to relative annual percentages to see the take-up rates. These are shown as Table 2. Figure 2 indicates that the highest percentage of take-up has been from 1994 sales when some 55 per cent had been taken-up. The lowest take-up rates occurred from sales in 1992. Only 22 per cent of parcels sold as vacant industrial land in 1992 had changed use by the date of the Valuation List in 1996. In essence, this means that some 62 per cent of land sold as vacant industrial land from 1991 to 1995 remained vacant as of 1996 and could be considered still as a part of the vacant industrial land stocks. Of the 38 per cent of land that taken-up, not all had been converted to industrial or commercial uses. Some has been rezoned, while other parcels had been used for non-commercial or non-industrial uses. The data has been split to show the current land use of sales by year of sale. The results are shown as volumes in Table 4 and the relative percentages are shown in Table 3 and Figure 3.

Figure 3 shows that, while there has been some take-up of vacant industrial land, a large amount of the take-up has been for non-commercial or non industrial purposes. The land use classifications are based upon the Land Use Codes of the Valuer General. Under this classification, uses such as warehouses and showrooms are classified as commercial. The results show that over the period 1991 to 1995 , some 17.6 per cent only of vacant industrial land sales have been developed for commercial or industrial land use. Significant amount of land have been used for residential activities (2.4 per cent overall), while some 4.5 per cent have been devoted to public utilities. Some of the non-commercial-industrial take-up may be due to rezoning. 
Figure 1: Volume of sold parcels each year which had changed use by 1996

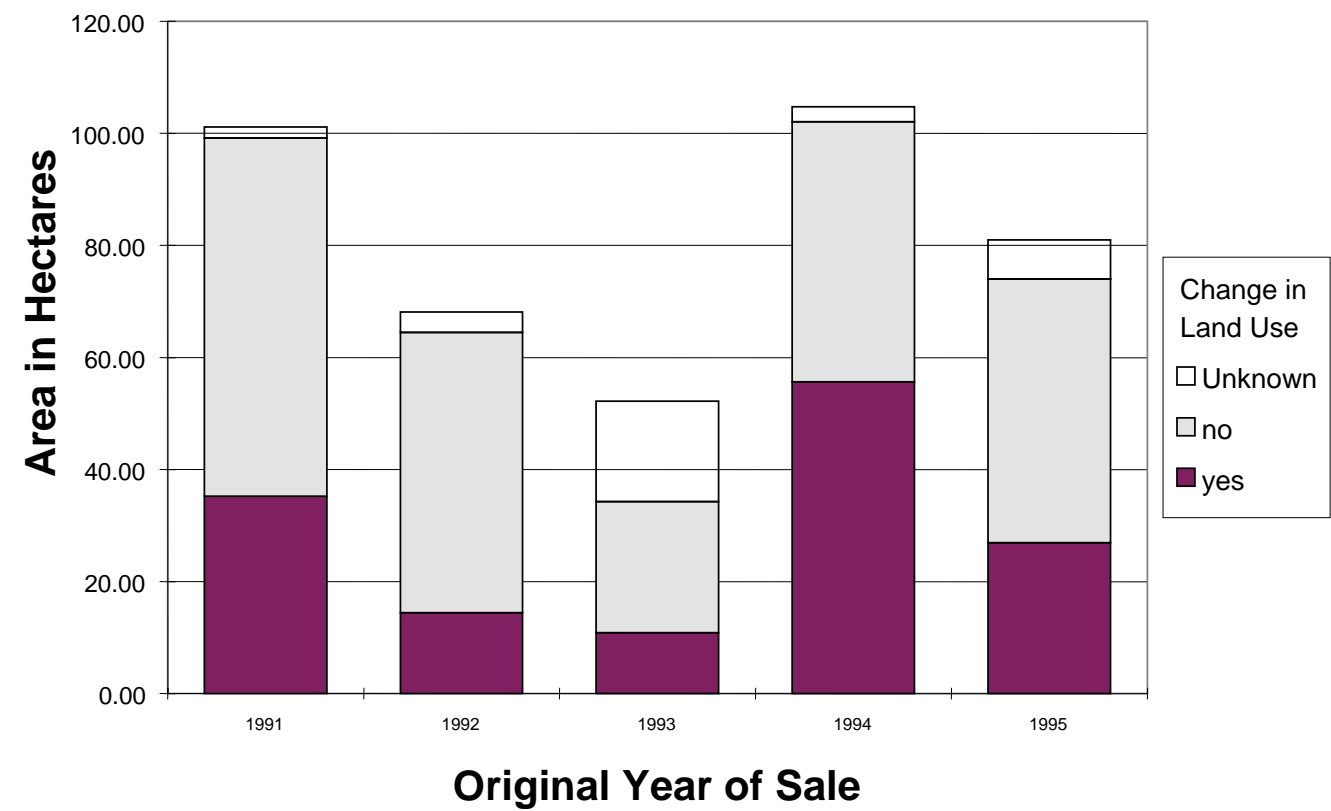

Table 2: Take-up rates (\%)

\begin{tabular}{||l|l|l|l|l|l|l||}
\hline \hline TAKEN-UP & 1991 & 1992 & 1993 & 1994 & 1995 & TOTAL \\
\hline NO & 64 & 78 & 68 & 45 & 64 & 62 \\
\hline YES & 36 & 22 & 32 & 55 & 36 & 38 \\
\hline TOTAL & 100 & 100 & 100 & 100 & 100 & 100 \\
\hline
\end{tabular}


Figure 2: Volume of sold parcels each year which changed use by 1996 (as a percentage of "known" sales in each year)

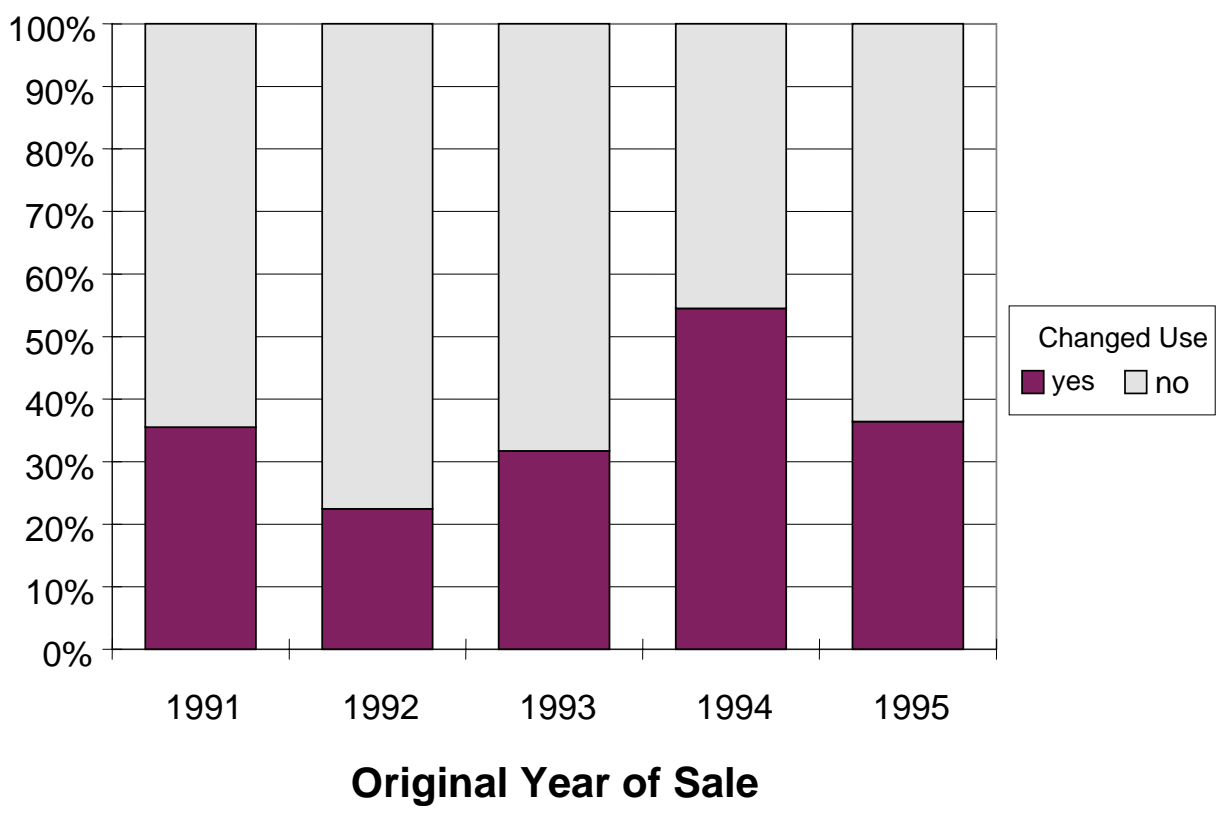

Table 4 - Current use of sales -by year

\begin{tabular}{||l|l|l|l|l|l|l|l||}
\hline \hline & $\begin{array}{l}\text { CURRENT } \\
\text { USE }\end{array}$ & \multicolumn{5}{l||}{ YEAR OF ORIGINAL SALE } & \multicolumn{2}{l||}{ TOTAL } \\
\hline & 1991 & 1992 & 1993 & 1994 & 1995 & hectares & $\begin{array}{l}\% \text { of TOTAL } \\
\text { hectares }\end{array}$ \\
\hline Commercial & 19.55 & 6.55 & 2.52 & 10.59 & 9.04 & 48.25 & 11.8 \\
\hline Industrial & 5.42 & 4.27 & 1.83 & 3.42 & 8.69 & 23.62 & 5.8 \\
\hline Residential & 1.12 & 3.25 & 0.12 & 2.88 & 2.21 & 9.58 & 2.35 \\
\hline Utility & 9.08 & 0.39 & 4.80 & 1.82 & 1.46 & 17.54 & 4.3 \\
\hline Vacant & 63.97 & 50.01 & 25.01 & 83.32 & 52.62 & 274.93 & 67.5 \\
\hline Unknown & 2.00 & 3.64 & 17.94 & 2.71 & 7.00 & 33.29 & 8.1 \\
\hline TOTAL & 101.15 & 68.11 & 52.21 & 104.74 & 81.01 & 407.22 & 100 \\
\hline
\end{tabular}


Figure 3: Volume of sold parcels by current land use (as a percentage of 'known' sales in each year)

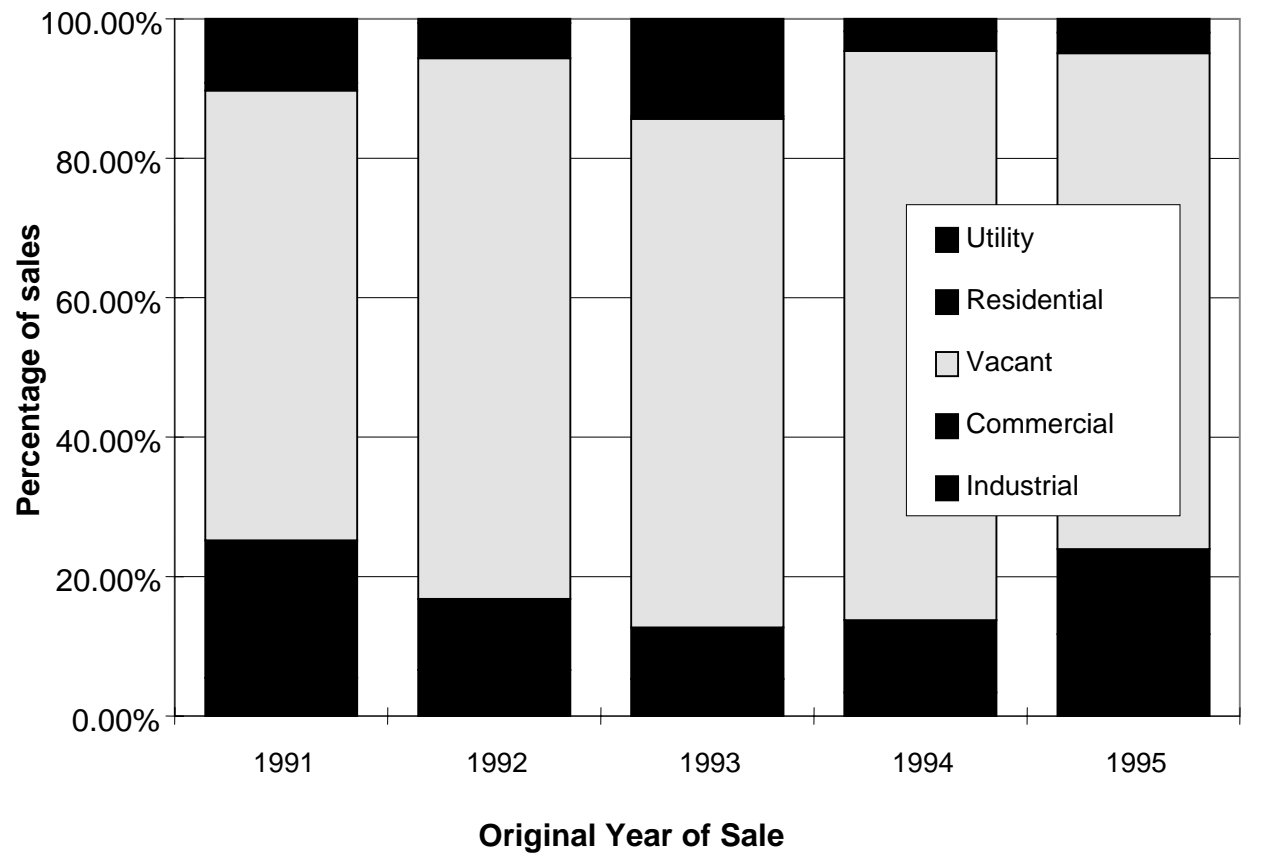

There is evidence from the data that some residential property is being developed on land zoned for industrial development while some other land is being rezoned. However, rezoning had only a minor effect with only 2 per cent of properties rezoned after sale. However, this does not indicate the amount of industrially zoned land which has been rezoned. Land rezoned prior to sale is not included in this analysis.

\section{SPATIAL DISTRIBUTION OF TAKE-UP RATES}

In order to gain a better picture of the spatial take-up of industrial property, the sales were classified into a number of regions. The regions were based on volume of sales as well as similarity of industrial attributes. The regions used are shown in Figure 4. 
Figure 4: Industrial regions of Adelaide - based on LGA boundaries

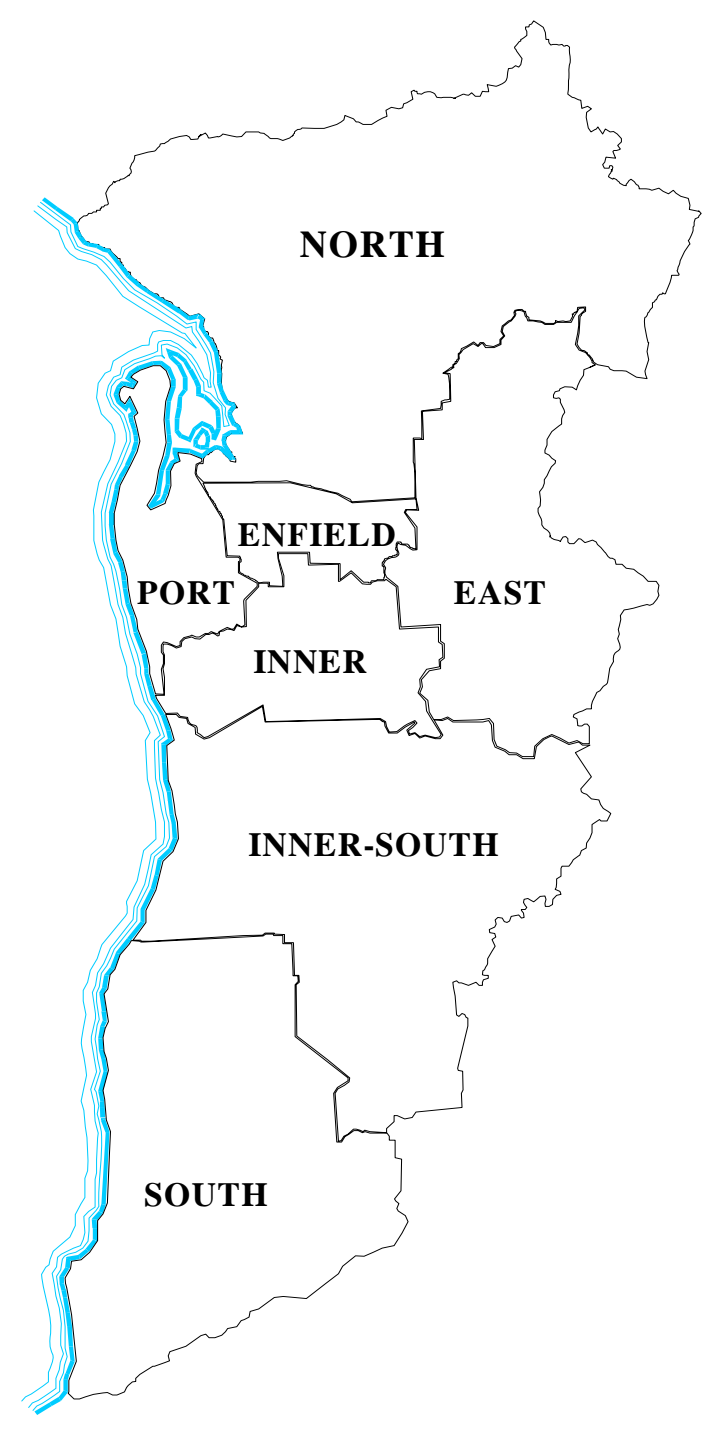


Figure 5: Location of vacant land sales (1991-1995): total hectares

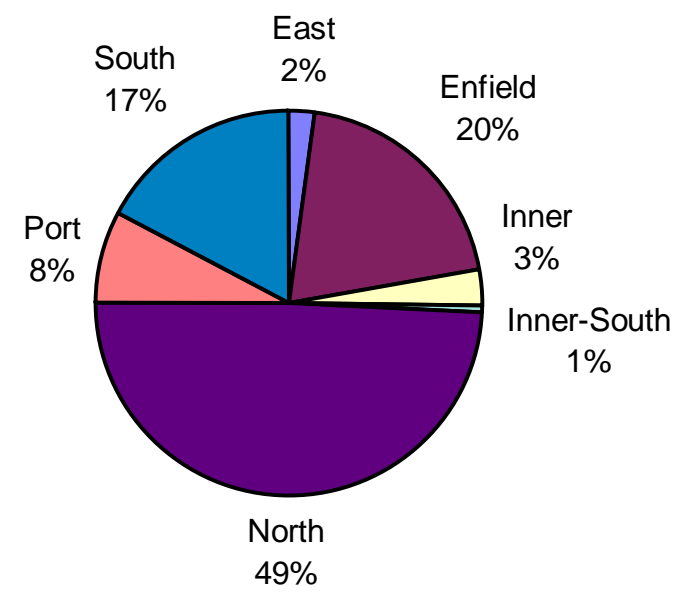

Figure 5 shows the distribution of sales by region. Nearly 50 per cent of the vacant industrial land sales were in the northern region comprising the LGAs of Salisbury, Elizabeth, Munno Para and Gawler. The Inner and Inner South Regions had less than five per cent of all sales. Figure 6 also shows the considerable differences in land uses which have been taken-up in each location. It is evident that some locations, particularly the eastern region, have little or no take-up of land for industrial or commercial purposes. By comparison, the inner-south region (while having very few sales) tends to be taken up for commercial-industrial purposes or left vacant. 


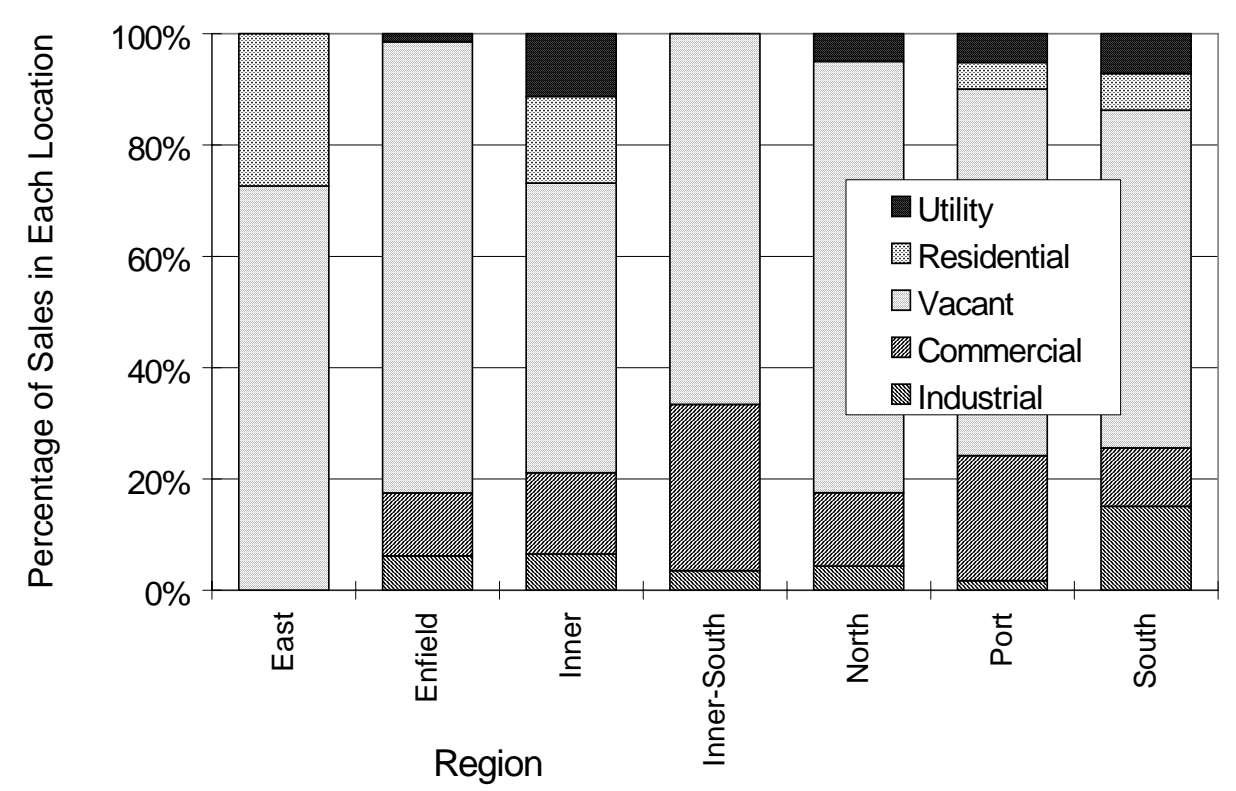

\section{IMPROVEMENTS TO VACANT LAND}

With a change of land use, there is usually some form of physical improvement. However, this may not always be the case. For example, several sites analysed within the study were listed as commercial land use, yet had no major improvements as they were being used for car parking. Awareness of such alternate uses provides important insights into the volume of land which is actually vacant. Table 5 which shows current improvements on vacant industrial land also provided an important insight into the types of improvement being made on land suitable for industrial development. The vast majority of vacant industrial land, 73 per cent, remained as land only. The most common improvements were officewarehouses. Factory buildings had been constructed on only 4 per cent of the land sold as vacant industrial stock. 
Table 5: Current improvements on vacant industrial land sold from 1991-1995

\begin{tabular}{lc}
\hline Improvements & Percentage of Land Area \\
\hline Land Only & $73.06 \%$ \\
Office -Warehouse & $6.45 \%$ \\
Other & $4.46 \%$ \\
Factory & $4.24 \%$ \\
House & $2.32 \%$ \\
Workshop & $1.79 \%$ \\
Warehouse & $1.61 \%$ \\
Shed & $1.60 \%$ \\
Office -Factory & $1.49 \%$ \\
Office -Workshop & $1.48 \%$ \\
Yard & $0.41 \%$ \\
Showroom-Warehouse & $0.39 \%$ \\
Town House & $0.24 \%$ \\
University Buildings & $0.17 \%$ \\
Office & $0.15 \%$ \\
Post Office & $0.14 \%$ \\
\hline
\end{tabular}

\section{CONCLUSION}

In conclusion, the actual take-up rate of sales of vacant industrial land varies in terms of how take-up is defined. For the purposes of this study, a pragmatic methodology has been proposed which offers some insights into the amount of vacant land actually available for industrial development, which could be underestimated if deduced from sales alone. In this study, some 38 per cent of the land had changed use and could be considered to be takenup. However, some 73 per cent of industrially zoned land had no substantial improvements up to five years after sale. It could be argued that these sites are still available for development and, as such, only 27 per cent of vacant industrial land has been fully takenup. Only 19 per cent of vacant land sold was converted to commercial or industrial use. This gives a clearer indication of the real demand for land for commercial industrial purposes. Also, it is important to note the extent to which take up rates can vary significantly over time and across different regions. An important extension of the research could be a qualitative study as to why owners of vacant industrial land are passive or active in terms of land improvement. 


\section{REFERENCES}

Adams, D., Disberry, A., Hutchinson, N., \& Munijoma, T. (2001) Journal of Property Research, 18(3), 217-234.

Adams, C., Russell, L. \& Taylor-Russell, C. (1995) Market activity and industrial development, Urban Studies, 32(3), 471-489.

Australian Bureau of Statistics, (2003) Labour Force, Australia. Cat. No. 6302.0. Canberra: AGPS.

Australian Bureau of Statistics, (2004) Australian Labour Market Statistics. Cat. No. 6105.0. Canberra: AGPS.

Ball, R.M. (1989) Vacant industrial premises and local development: a survey, analysis and policy assessment of the problem in Stoke-on-Trent, Land Development Studies, 6, 105128.

Blair, J. \& Yardley, R. (1991) Planning for industrial land in the Sydney region, Australian Planner, 16-21.

Gibb, K. (2004) Policy priorities for property and land in Central Scotland, Journal of Property Research, 21(3), 255-277.

Jortberg, R. (1996) Retail market analysis: an intermediate approach to estimate demand, The Appraisal Journal, 423-429.

Stimson, R. (2001) Dividing societies: the socio-political spatial implications of restructuring in Australia, Australian Geographical Studies, 39(2), 198-216.

Stimson, R., O'Connor, K., \& Taylor, S. (1997) Five cities: patterns of employment and labour force characteristics in Australia's metropolitan cities. Melbourne: AHURI.

Tsolacos, S. (1997) A case study of industrial property development in South Hampshire, Journal of Property Research, 14(3), 211-236.

Tsolacos, S. (1995) Industrial property development in the UK: a regional analysis of new orders, Journal of Property Research, 12, 95-125.

Wheaton, W \& Torto, R (1990) An investment model of the demand and supply for industrial real estate, AREUEA Journal, 18(4), 530-547.

Wincott, D.R. \& Mueller, G (1995) Market analysis in the appraisal process, The Appraisal Journal, 27-32. 